\section{Life (and death) in Lake Nyos}

SiR-Walter Shearer' asked what effect the 1986 disaster that killed more than 1,700 people to the north of Lake Nyos, Cameroons, had had on life, particularly fish, in the lake. Shearer should be thanked for drawing this interesting question to our attention and for pointing out that there have been studies of the fish in other volcanic lakes in Cameroon. But the published reports of the British Scientific Mission' and the American group", and unpublished Mission reports of the French, Italian or Japanese teams make no mention of life (or death) in the lake.

When I went to Cameroon, as part of the British Scientific Mission, in early September 1986, I was expecting to find that there had been a fish-kill in Lake Nyos and wondered what it would tell us about the composition of the toxic gas. At that time there were many theories in the air but little evidence concerning the nature of the event. However, when we got to Lake Nyos we found that there were no dead fish in the lake, no certain reports of dead fish and no canoes or fish traps near the lake. And local people who knew the area well were able to confirm that there had been no fish in the lake prior to the disaster. So the simple answer to Shearer's question "what happened to the fish that were living in Lake Nyos?", is that there were no fish. I would suspect that the general failure to mention the apparent absence of fish in Lake Nyos reflects the natural tendency of scientists to concentrate on positive rather than negative evidence. But negative evidence can sometimes be very important, and I think this may be just such a case.

Water from Lake Nyos is discharged over a natural weir which has a free fall of $22.3 \mathrm{~m}$, so although there are fish in the streams and rivers near to the lake they have no direct access into the lake. But as Shearer has pointed out there are endemic species of cichlid fish in crater lakes, access to which must also be restricted (otherwise the species would not be endemic). To transfer a breeding population of cichlid fish into an isolated lake, by natural means, presents less of a problem than it would for most other groups of fish as cichlids are mouth brooders. So it would need only one brooding parent to be taken by a bird of prey and dropped, dead or alive, into an otherwise isolated lake.

If lake Nyos were extremely young that might offer a possible explanation for the absence of fish. But Lake Nyos is, in my opinion, of a similar age to the other isolated volcanic lakes in which there are a number of species of fish.

There is no reason to suspect that under normal circumstances the waters of Lake Nyos would be hostile to naturally intro- duced fish. From the limited amount of chemical data available (mainly in unpublished mission reports) we can be reasonably sure that prior to the disaster the surface water was well oxygenated, mildly acid, and did not contain high concentrations of potentially toxic ions.

The available evidence, some of which is outlined above, leads me to conclude that breeding populations of fish must surely have been introduced into Lake Nyos on a number of occasions. But that whenever this has happened a subsequent lake overturn, similar to that which caused the August 1986 disaster, completely deoxygenated the surface water and killed off all the fish. As there were no fish in the lake before the recent disaster the probability must be that major gas releases are rather more frequent than the natural introduction of viable fish populations I would speculate that major gas releases might occur every 50 years or so.

Although we did not find any fish in Lake Nyos that does not mean to say that the lake waters were completely lifeless at the time of our visit. Whilst examining the south-western margin of the lake I came across an apparently healthy population of frogs living by the side of the lake and hopping in and out of the water without apparent ill effect. If any expert on West African frogs or on the tolerance of frogs in general to toxic gases should happen to read these comments I would be very pleased to hear from them.

Department of Earth Sciences

University College of Swansea,

Swansea SA2 8PP, UK

1. Shearer. W. Nature 328. 299-300) (1987)

2. Freeth, S.J. \& Kay. R.L.F. Nature 325, 1114-105 (1987)

3. Kling, G.W. et al. Science $236169-175$ (1987)

\section{The electronic structure of the benzene molecule}

SIR-I wish to comment on the interesting conclusions $^{1-9}$ obtained from recent $a b$ initio calculations for $\mathrm{C}_{6} \mathrm{H}_{6}$ (refs 1,8$)$ and to relate them to the earlier work of Linnett, Cooper, Gerratt and Raimondi ${ }^{1}$ show that resonance between the Kekule and Dewar valence bond (VB) structures (1)(5) generates a lower energy than does the self consistent field (SCF) molecular orbital (MO) wave function and therefore,

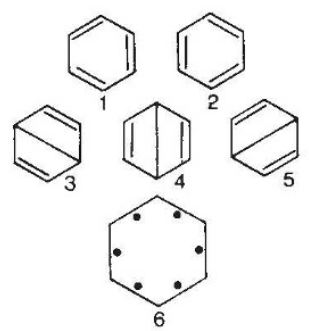

to a good approximation, there is no delocalization of the six $\pi$ electrons.

In 1965, Empedocles and Linnett ${ }^{10}$ calculated that the $\pi$ electron energy for resonance between the Kekulé structures, with the Heitler-London formulation for the $\pi$ electron wave functions, also lies below the SCF-MO energy for these electrons. No spatial optimization of the atomic orbitals (AOs), that is, no spreading of each AO towards its neighbour ${ }^{2}$, was involved.

Linnett and his coworkers (ref. 11 and refs therein) obtained a similar result for resonance between two covalent structures of some systems that involve three-electron and three-overlapping $\mathrm{AO}$ bonding units-for example, $\mathrm{H}_{3}$ (three $\sigma$ electrons) and $\mathrm{C}_{3} \mathrm{H}_{5}, \mathrm{NO}_{2}, \mathrm{HCO}_{2}$ and $\mathrm{O}_{3}^{+}$(each with three $\pi$ electrons in the calculations). The covalent structures for each of these systems (for example $\dot{\mathrm{H}} \mathrm{H}-\mathrm{H}$ and $\mathrm{H}-\mathrm{H}$ $\dot{\mathrm{H}}$ for $\mathrm{H}_{3}$ ) correspond to the Kekule structures for $\mathrm{C}_{6} \mathrm{H}_{6}$; each overlapping $\mathrm{AO}$ is singly-occupied and bonding occurs between pairs of adjacent atoms.

Lower energies were, of course, obtained when the one-centre AOs of the Kekulé-like structures were replaced by spatially-optimized orbitals ${ }^{12}$ in the Heitler-London wave functions for these systems. ${ }^{1}$. Even lower energies were calculated $^{10,11}$ for Linnett's non-paired spatial orbital (npso) structures such as (6) for $\mathrm{C}_{6} \mathrm{H}_{6}$, in which each of the $\pi$ electrons is located in a separate two-centre bonding MO. Thus, as Linnett often stressed ${ }^{13}$, the npso structure for $\mathrm{C}_{6} \mathrm{H}_{6}$, with localized (one-electron) $\pi$ bonds, provides a better VB representation than does resonance between the Kekulé structures.

Messmer and Schultz ${ }^{8}$ have also calculated that resonance between the Kekule structures gives a lower energy than does the SCF-MO configuration; they have also provided theoretical evidence that the double bonds of the Kekulé structures may be bent rather than $\sigma$ and $\pi$. Bent bond descriptions ${ }^{13}$ also obtain for twelve of the $\mathrm{C}-\mathrm{C}$ bonding electrons in Linnett's double quartet representation of the npso structure (6).

As indicated by Cooper, Gerratt and Raimondi, interconversion between the Kekule structures (1) and (2) may be achieved by changing the spin-pairings. For electron-rich systems with four-electrons and three overlapping $\mathrm{AO}$ bonding units, such as, $\mathrm{H}_{3}^{-}, \mathrm{O}_{3}$ and $\mathrm{C}_{3} \mathrm{H}_{5}^{-}$, electron delocalization is required in order to convert one Kekulé-like structure (for example, $\ddot{\mathrm{H}}^{-} \mathrm{H}-\mathrm{H}$ for $\mathrm{H}_{3}^{-}$) into the other $\left(\mathrm{H}-\mathrm{H} \quad \ddot{\mathrm{H}}^{-}\right)$. When Dewar-like structures with long or formal bonds (for example, $\left.\dot{H} \quad \ddot{H}^{-} \dot{H}\right)$ are also included in the resonance scheme, resonance has been calculated to generate a substantially lower (four-electron) energy than does the corresponding SCF-MO wave function $^{14-16}$. The relevance of this type of result for qualitative descriptions of bonding has been discussed ${ }^{17}$, primarily via 